Article

\title{
Profiling of Chemical and Structural Composition of Lignocellulosic Biomasses in Tetraploid Rice Straw
}

\author{
Chen Chen ${ }^{1,2, \dagger}$, Zhixiong Chen ${ }^{3, \dagger}$, Jiajun Chen ${ }^{1,2}$, Jiawei Huang ${ }^{1,2}$, Huiling $\mathrm{Li}^{1,2}$, \\ Shaolong Sun ${ }^{4}\left(\mathbb{D}\right.$, Xiangdong Liu ${ }^{1,3} \mathbb{D}$, Aimin $W u^{1,2}$ and Bo Wang ${ }^{1,3, * \mathbb{D}}$ \\ 1 State Key Laboratory for Conservation and Utilization of Subtropical Agro-Bioresources, Guangzhou 510642, \\ China; cc@cch3n.cn (C.C.); chenjiajun1001@126.com (J.C.); jiaweihuangkawy@gmail.com (J.H.); \\ lihl@scau.edu.cn (H.L.); xdliu@scau.edu.cn (X.L.); wuaimin@scau.edu.cn (A.W.) \\ 2 Guangdong Key Laboratory for Innovative Development and Utilization of Forest Plant Germplasm, College \\ of Forestry and Landscape Architectures, South China Agricultural University, Guangzhou 510642, China \\ 3 The Key Laboratory of Plant Molecular Breeding of Guangdong Province, College of Agriculture, South \\ China Agricultural University, Guangzhou 510642, China; chenzx@scau.edu.cn \\ 4 College of National Resources and Environment, South China Agricultural University, Guangzhou 510642, \\ China; sunshaolong328@scau.edu.cn \\ * Correspondence: bowang@scau.edu.cn \\ + These authors contributed equally to this work.
}

Received: 21 December 2019; Accepted: 20 January 2020; Published: 5 February 2020

check for updates

\begin{abstract}
The improvement of the saccharification of rice straw is one of the strategies to reduce the sophisticated pretreatment that results in high cost and is unfriendly to the environment. We explored the cell wall features in tetraploid rice and highlighted the enhanced saccharification of tetraploid with large biomass. Results showed that lignin content and S/G ratio reduced to $17.09 \%$ and 0.37 , respectively, in tetraploid straw by the determination of the pyGC-MS method. After the pretreatment, the cellulose crystallinity index decreased from $63.22 \%$ to $57.65 \%$ in tetraploid straw, which is lower than that of pretreated diploid straw. Surface topological analysis of SEM images indicated that tetraploid straw was more susceptible to the pretreatment. Tetraploid straw showed a strong advantage in the process of enzymatic hydrolysis. The enzyme efficiency reached the highest value of $77.60 \%$, and the rate of enzyme reaction was improved to make the reaction saturated earlier than conventional rice. We concluded that the high saccharification has resulted from the alteration of lignin and cellulose in tetraploid rice. Our research provides an improved green feedstock for bioenergy, and the tetraploid rice straw shows the potential utilization value in bioethanol production.
\end{abstract}

Keywords: tetraploid rice; enzymatic saccharification; cell wall; lignocellulose; composition

\section{Introduction}

As one of the renewable energy sources, biomass energy has advantages in a sustainable and favorable environment. Research of biomass energy mainly focused on lignocellulose, which consists of cellulose, hemicellulose, and lignin [1]. Rice is one of the world's main crops, with its vast acreage and yield, but is also an excellent renewable energy resource. The biomass of straw cell wall is usually composed of 35\% 50\% cellulose, 20\% 35\% hemicellulose, and 10\% 25\% lignin in rice. Conventional rice is biologically diploid $(2 \times=24)$, and tetraploid rice $(4 \times=48)$ is produced by chromosome duplication. The polyploid plant is significantly different from diploid plants, including morphology, yield, total biomass, cell wall composition, cell size, etc. [2-6]. For biomass resources, the cell wall structure is often damaged by pretreatment to make it more susceptible to utilization, whereas, the polyploid plant has been characterized by changes in cell wall structure [4], revealing the potential roles in bioenergy fields. 
Cellulose is the most abundant component in the cell wall. The cellulose molecule exhibits a linear distribution of stretching with $\beta$-D-pyranoglucoside and forms crystalline cellulose easily [7]. The low crystalline cellulose may affect the structure or accessibility of other polysaccharides, resulting in prompt degradation of cellulose [8]. Moreover, the cellulose $\mathrm{H}$ bonds functions to maintain the stability of cellulose. There are two kinds of $\mathrm{H}$ bonds in plant cellulose, which are intramolecular $\mathrm{H}$ bond and intermolecular $\mathrm{H}$ bond [9]. Breakage of these $\mathrm{H}$ bonds loosens cellulose structure, reduces the crystallinity and enhances the enzymatic hydrolysis efficiency of cellulose. Interestingly, it has been reported that the polyploid cellulose fiber length is higher than that of diploid poplar [4]. Studies in rice have shown that cellulose content is positively correlated with chromosome multiples, while lignin is negatively correlated [10].

Studies on lignin changes in polyploid plants have been reported in several pieces of literature. These changes mainly focused on the reduction in lignin content in the cell wall [4]. The structures of lignin in rice straw include syringyl lignin (S), guaiacyl lignin (G), and hydroxy-phenyl (H) lignin. Not only the ratio of syringyl lignin and guaiacyl lignin $(S / G)$ affects the separation of lignin, but the lignin content also determines the sensitivity of the straw material to enzymes or other treatments [11-13]. Besides, the hemicellulose filled between cellulose and lignin can affect the cell wall utilization in plant as well [14]. The hemicellulose structure varies among different species or varieties [15]. Though the hemicellulose contents do affect the utilization of biological materials [10], the connection between hemicellulose and polyploids is unclear at present.

Compared to common diploid and transgenic plants, tetraploid rice has an enhanced yield, powerful biological potential, environmental adaptation, and considerable biomass [16]. Agronomic traits, such as larger grain size, stronger stem, and longer panicles of tetraploid, are genetically stable and identical. Whereas, the research on the chemical and structural composition of lignocellulosic biomasses in polyploid plants, especially the tetraploid rice, is missing. To explore the potential value of tetraploid rice in the bioenergy utilization, the cell wall compositions and enzymatic saccharification were characterized in tetraploid straw with the supportive evidence of XRD, FT-IR, SEM. The results demonstrated that the changes in cell wall structure resulted in the enhanced saccharification degree in tetraploid rice, making it the promising green biomaterials.

\section{Materials and Methods}

\subsection{Plant Materials and Biomass Sample Preparation}

Both the diploid rice and tetraploid rice were obtained from the experimental field of Agricultural College in South China Agricultural University (Guangzhou, China). The tetraploid rice (Aijiaonante- $4 \times$ ) was cultivated from Aijiaonante- $2 \times$ by chromosome doubling using colchicine treatment. Ten individual plants were harvested at mature stages. Leaves, including blades and sheathes, were removed from stems. The stems were dried at $60{ }^{\circ} \mathrm{C}$ for $24 \mathrm{~h}$, then the dried straw segments were crushed by a crusher for $1 \mathrm{~min}$ and screened with sieved nets ( 40 to 60 mesh) for further analysis. The samples were dewaxed by the soxhlet extraction method for $5 \mathrm{~h}$ with 2:1 $(v / v)$ acetone-ethanol at $90^{\circ} \mathrm{C}$, then air-dried at room temperature to obtain the alcohol-insoluble residue (AIR). This process is shown in Figure 1.

\subsection{Cell Characteristic Observation by Microscope}

The straw slices $(65 \mu \mathrm{m})$ were obtained by vibratome (Leica VT1000 S, Leica Microsystems, Buffalo Grove, IL, United States) and dyed with $0.2 \%$ toluidine blue (m/v). After $1 \mathrm{~min}$ of dyeing, the excess dye was washed with $70 \%$ ethanol. The dyed slices were observed under a scanning microscope (Wanbang M8). Cell number and cell size were calculated by using ImageJ software (LOCI, University of Wisconsin, WI, USA, https://imagej.nih.gov/ij/). 


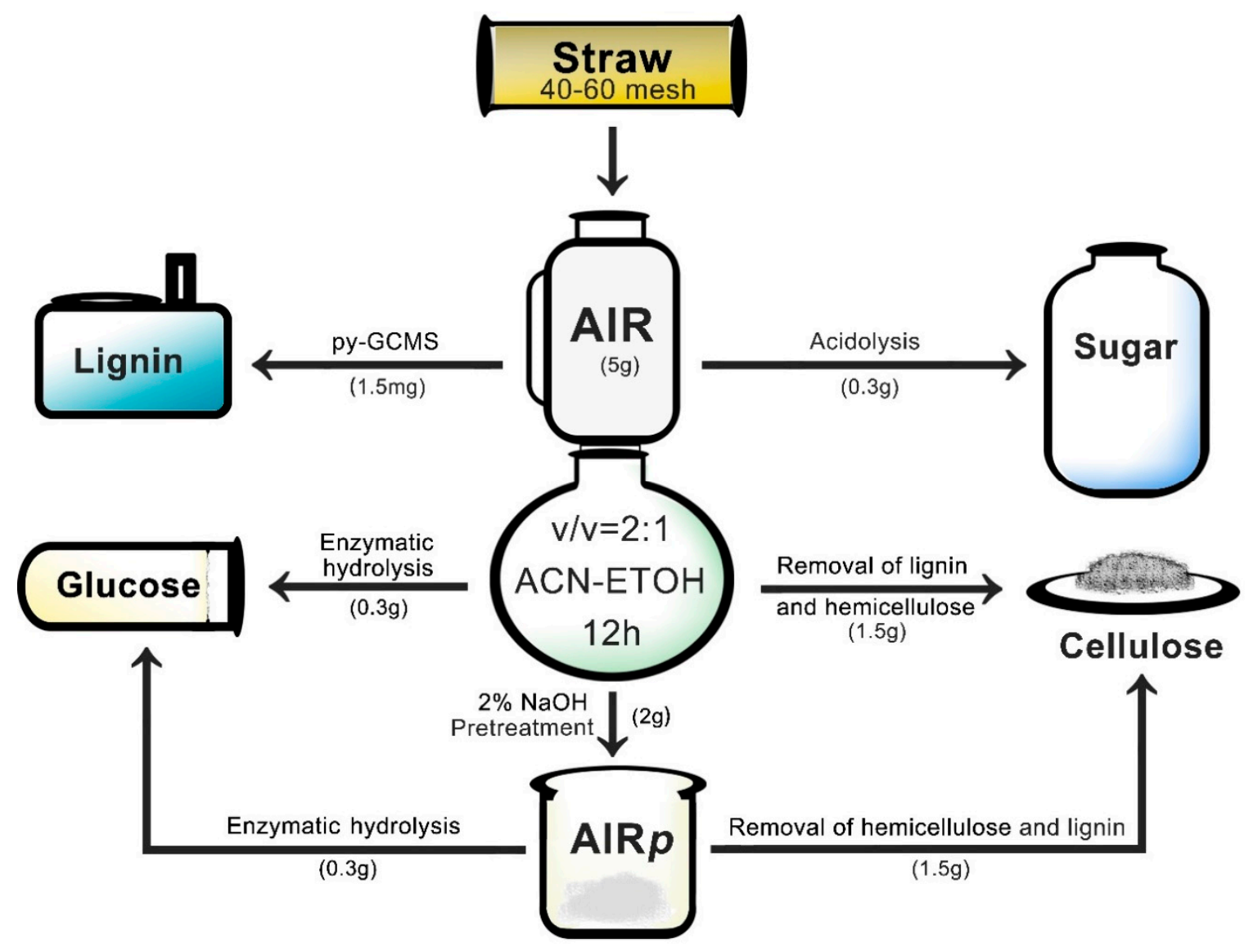

Figure 1. Schematic illustration of the experimental process.

\subsection{Material Composition Analysis}

Cell wall composition analysis was performed using a stepwise acid hydrolysis method. AIR ( $0.3 \mathrm{~g})$ was taken and acidified by using $72 \%$ sulfuric acid $(3 \mathrm{~mL})$ at $30{ }^{\circ} \mathrm{C}$ for $1 \mathrm{~h}$ and then treated at $121^{\circ} \mathrm{C}$ for $1 \mathrm{~h}$ with the addition of $84 \mathrm{~mL}$ of deionized water. After cooling, it was filtered using a sand core funnel (G4). The diluted filtrate and the fine residue were filtered through $0.22 \mu \mathrm{m}$ nylon membrane for monosaccharide composition analysis by ion chromatography. The ion chromatogram (Metrohm 940, Herisau, Switzerland) equipped with the CarboPac PA10 column $(2 \mathrm{mM} \times 250 \mathrm{mM}$, Dionex, Sunnyvale, CA, USA) and coupled with a PAD detector was used for quantification. $\mathrm{NaOH}(20 \mathrm{mM})$ was added as an isocratic eluent and eluted at a flow rate of $0.5 \mathrm{~mL} / \mathrm{min}$ for $20 \mathrm{~min}$. The program was set to $0-75 \mathrm{mM} \mathrm{NaAc} 15 \mathrm{~min}$ for gradient elution, $200 \mathrm{mM} \mathrm{NaOH} 10 \mathrm{~min}$ for washing, and then $20 \mathrm{mM} \mathrm{NaOH}$ for re-equilibration. A calibration curve was established to calculate the quantification of the monosaccharide.

The acidified elute was diluted ten times, and the percentage of the sample content was calculated by the following formula:

$$
\% \text { Comtent }=\frac{D \times V_{1} \times 10^{-6} \times P \times 0.9}{M} \times 100 \%
$$

where $D$ was the dilution factor of acidified elute $(10 \times), V_{1}$ was the total liquid volume used for hydrolysis $(V=86.663 \mathrm{~mL}), P$ was the concentration determined by ion chromatography $(\mathrm{mg} / \mathrm{L})$, and the $M$ was the weight of AIR. 


\subsection{Isolation of Hemicellulose and Cellulose}

Lignin was removed from AIR samples using $0.1 \mathrm{~mol} / \mathrm{L}$ sodium chlorite-acetic acid solution (acetic acid, 1:100(v/v)) for $4 \mathrm{~h}$ at $75^{\circ} \mathrm{C}$ for hemicellulose and cellulose isolation. The hemicellulose was extracted at $50{ }^{\circ} \mathrm{C}$ using $0.5 \mathrm{M} \mathrm{KOH}$. The solid-liquid mixture was filtered and separated into pellet and filtrate. The filtrate was neutralized with acetic acid, and three volumes of $95 \%$ ethanol were added to precipitate hemicellulose. Finally, the liquid was further lyophilized to collect hemicellulose. On the other side, the pellet was used for cellulose extraction. The cellulose was obtained by $\mathrm{KOH}$ gradient washing and eluted with $80 \% \mathrm{DMSO}$ at $80{ }^{\circ} \mathrm{C}$ for $5 \mathrm{~h}$ to remove the remaining hemicellulose.

\subsection{The Ash Determination}

The determination of ash was carried out by a rapid ashing method using a muffle furnace. The ash dish was burned to constant weight before the determination. AIR ( $1 \mathrm{~g})$ was evenly spread in the container, and the ash dish was slowly pushed into a muffle furnace at $850{ }^{\circ} \mathrm{C}$ for $40 \mathrm{~min}$. The weight was recorded after cooling to room temperature.

\subsection{Enzymatic Hydrolysis}

The hydrolyzed samples consisted of AIR and pretreated AIR by $2 \% \mathrm{NaOH}\left(60^{\circ} \mathrm{C}, 6 \mathrm{~h}\right)$. AIR $(0.3$ g) was dissolved in $30 \mathrm{~mL} 0.1 \mathrm{M} \mathrm{NaAC}-\mathrm{HAC}$ buffer $(\mathrm{pH}=4.5)$. The cellulase $(10 \mathrm{FPU} / \mathrm{g})$ was chosen for the enzymatic hydrolysis analysis at $55^{\circ} \mathrm{C}$ for $4,12,24,48$, and $72 \mathrm{~h}$, respectively. After the enzymatic hydrolysis, the reaction liquid was deactivated and filtered through a $0.22 \mu \mathrm{m}$ filter. The concentrations of glucose were determined by ion chromatography. The hydrolysis efficiency of the enzyme was calculated as follows:

$$
\% \text { Enzymatic digestibility }=\frac{\left(D \times R \times V_{2}\right)}{\left(P \times V_{1}\right)} \times 100 \%
$$

where $R$ was the released glucose concentration by ion chromatography. $V_{2}$ was a volume of the enzymatic reaction liquid. $V_{1}, D$, and $P$ have the same meanings as above (see Section 2.3).

\subsection{Scanning Electron Microscope (SEM) Observation}

The sample was coated with a thin gold film. The model of the scanning electron microscope used was Zeiss HD (Zeiss Sigma HD, Jena, Germany) at $5 \mathrm{kV}$ acceleration voltage. The surface morphology of the straw was observed. Then, the energy spectrum sweeping (point scan) was performed to obtain semi-quantitative data of $\mathrm{Si}, \mathrm{Al}$, and Cd elements.

\subsection{Crystallinity Measurement}

The crystallinity of the straw was analyzed by X-ray diffraction (XRD) (D8 Bruker, Madison, WI, USA) at $40 \mathrm{kV}$ and $30 \mathrm{~mA}$ with copper radiation. The scanning angle was in the range of $5^{\circ}$ to $50^{\circ}$, and the scanning speed set to $2^{\circ} / \mathrm{min}$. The crystallinity index $(\mathrm{CrI})$ was calculated according to the following formula:

$$
\operatorname{CrI}(\%)=\left(I_{002}-\frac{I_{A m}}{I_{002}}\right) \times 100 \%
$$

where $I_{002}$ was the highest value of the peak at $22.04(2 \theta) . I_{A m}$ is the maximum value of the amorphous cellulose peak at $18.41(2 \theta)$.

\subsection{Fourier Transform Infrared Spectroscopy (FT-IR)}

The sample was ground with $\mathrm{KBr}$ in a ratio of $1: 100(\mathrm{~m} / \mathrm{m})$ to a fine powder and dried at $50{ }^{\circ} \mathrm{C}$ for $12 \mathrm{~h}$. The mixed sample was pressed into a sheet in compressing equipment for further FT-IR analysis (VERTEX 70, Ettlingen, Germany). A total of 40 scans were performed at a resolution of 4 $\mathrm{cm}^{-1}$. The absorption spectra were obtained from 2000 to $500 \mathrm{~cm}^{-1}$. 


\subsection{The Measure of Lignin Content and Composition by Pyrolysis GC/MS}

AIR (1.5 mg) was pyrolyzed in an EGA/PY-3030D pyrolyzer (Frontier Laboratories, Saikon Koriyama, Japan) connected to a QP2010 GC/MS system (Shimadzu, Kyoto, Japan) with a DB-5 capillary column ( $30 \mathrm{mM} \times 0.25 \mathrm{mM} \times 0.25 \mu \mathrm{m}$, Agilent, Santa Clara, CA, USA). The pyrolysis was heated from $200{ }^{\circ} \mathrm{C}$ (maintained for $1 \mathrm{~min}$ ) to $600{ }^{\circ} \mathrm{C}$ (maintained for $10 \mathrm{~s}$ ), and the rate of temperature rise was $20^{\circ} \mathrm{C} / \mathrm{min}$. The GC was heated from 40 to $280^{\circ} \mathrm{C}$, the rate of temperature rise was $5^{\circ} \mathrm{C} / \mathrm{min}$, and maintained $10 \mathrm{~min}$ at $280^{\circ} \mathrm{C}$. The flow rate of helium was $2 \mathrm{~mL} / \mathrm{min}$. The results were identified for compensation according to the standards of the Wiley and National Institute of Standards and Technology (NIST) libraries [17]. Finally, the peak area was calculated and normalized.

The composition results of straw by pyGC-MS include carbohydrate related (C), guaiacyl units $(\mathrm{G})$, syringyl units $(\mathrm{S})$, and p-hydroxyphenol units $(\mathrm{H})$. The generic benzene derivatives, which without $\mathrm{OH}$ group on the aromatic ring (but most probably originated from lignin related compounds) $(\mathrm{P})$, a substance that knows spectra information (unknown identification) (U) and unknown spectra (cannot be lignin or carbohydrates) (0), also were determined. Each substance was expressed as a percentage of the total $(\mathrm{C}+\mathrm{G}+\mathrm{S}+\mathrm{H}+\mathrm{P}+\mathrm{U}+0)$. The total lignin refers to $\mathrm{G}+\mathrm{S}+\mathrm{H}+\mathrm{P}$.

\section{Results and Discussion}

\subsection{Phenotypic Features of the Tetraploid Straw Cell Wall}

Tetraploid rice and diploid rice have significantly different agronomic traits, such as an increase in biomass and yield $[18,19]$. In order to explore the phenotypic feature of the cell wall in tetraploid rice straw, the slices from the fresh straw were observed using the microscope. The number and size of cells were analyzed by ImageJ software. Results showed that tetraploid rice had more cells and larger xylem vessels, which correlates to the large cell-size of tetraploid (Figure 2a,b). The most utilized ingredients of straw cell walls were epidermis, phloem, and xylem, which were thicker and more numerous (Figure 2c). It implies that the tetraploid straw has more available ingredients than conventional rice.

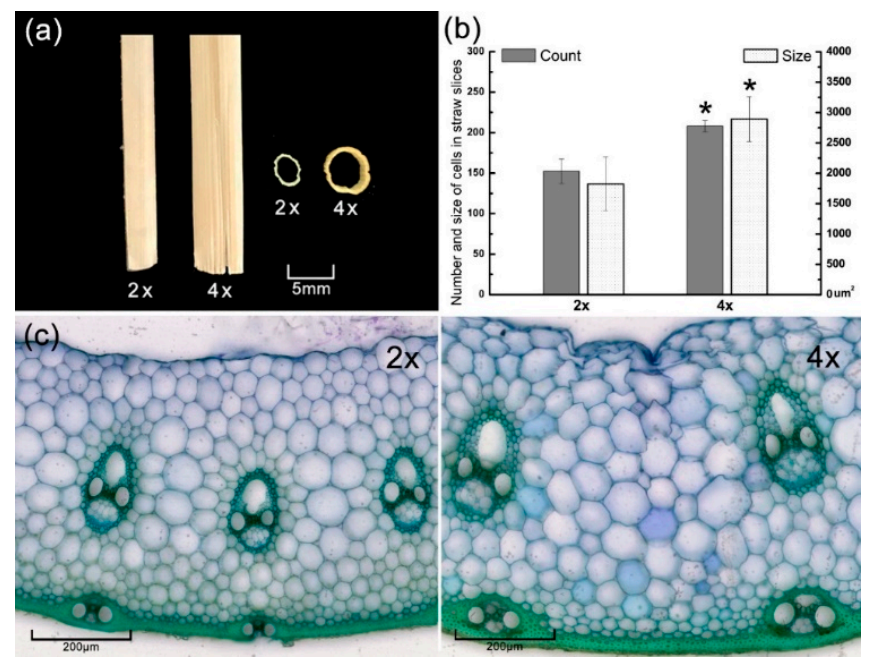

Figure 2. Straw morphology in diploid $(2 \times)$ and tetraploid $(4 \times)$ rice. (a) Straw phenotype. (b) Cell number and cell size calculated by ImageJ. (c) Straw slice dyeing with toluidine blue.

\subsection{Composition Analysis of the Tetraploid Straw}

It would be interesting to know whether these phenotypic changes alter the cell wall structure in the tetraploid. Therefore, polysaccharide components, lignin contents, and ash were investigated. The results of polysaccharide components presented the content of monosaccharides. Around half of the substance in the cell wall was cellulose, which contributed by the highest level of glucose. Glucose 
content in the tetraploid was 55.42\%, which is higher than that in the diploid (Figure 3). Xylose is the major sugar from hemicellulose, and it showed a significant decrease in tetraploid (Figure 3). The level of hemicellulose was $4.44 \%$ less than the diploid (Table 1). Arabinose plays the role of modification xylan main chain of hemicellulose polysaccharides. No significant change in arabinose content was detected, which means that the ratio of xylose and arabinose decreased. These results indicate a low branching degree of hemicellulose in the tetraploid.

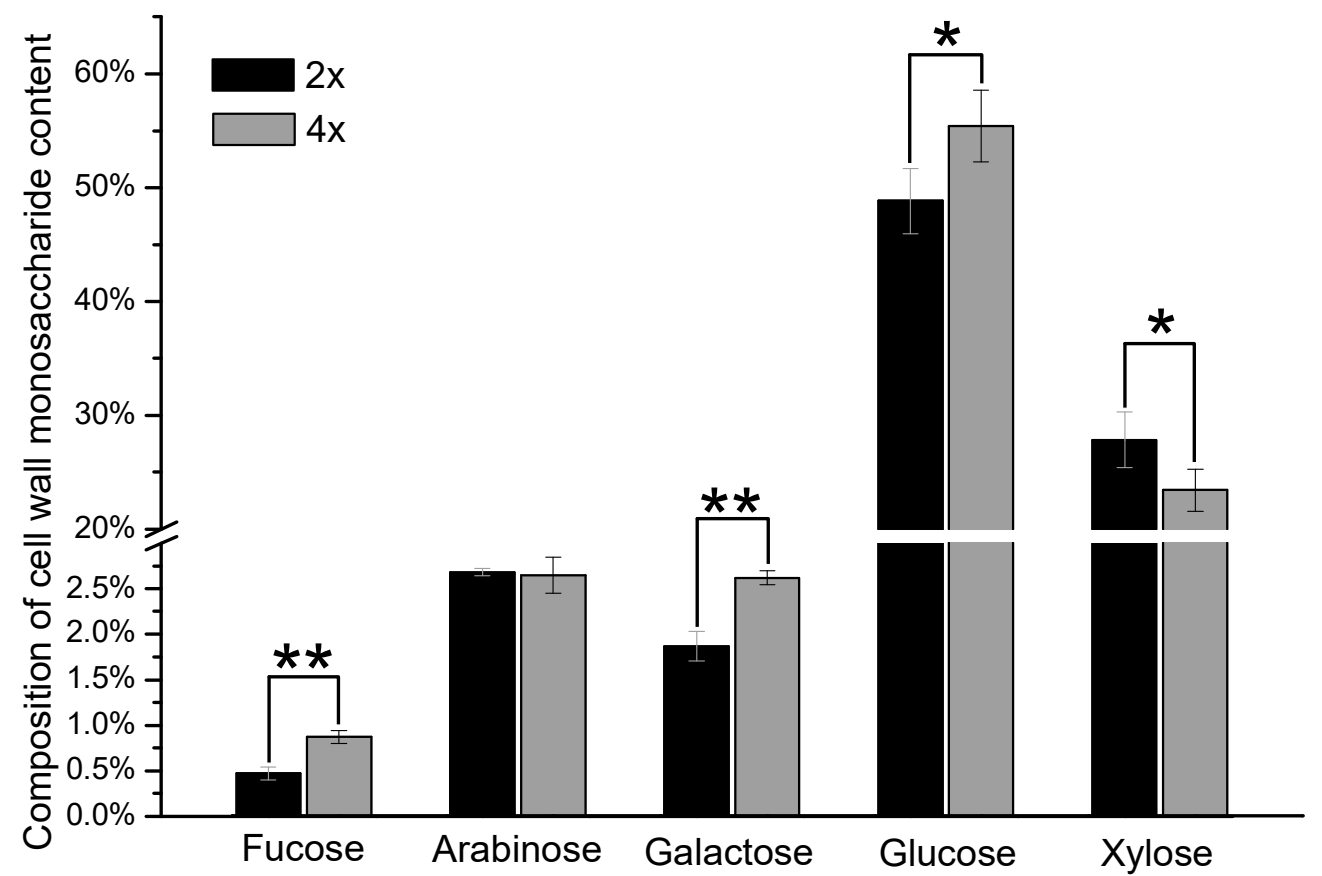

Figure 3. Monosaccharide component analysis of cell wall of tetraploid rice $(4 \times)$ and diploid rice $(2 \times)$. The significance analysis followed the student's $t$-test, ${ }^{* *}$ indicates $P \leq 0.01$, ${ }^{*}$ indicates $P \leq 0.05$.

Table 1. Composition of tetraploid straw cell wall.

\begin{tabular}{ccccccc}
\hline Sample & Hemicellulose (\%) & Lignin (\%) & S (\%) & G (\%) & S/G & Ash (\%) \\
\hline $2 \times$ & $30.51 \pm 2.15$ & $19.41 \pm 0.42$ & $3.32 \pm 0.09$ & $8.59 \pm 0.17$ & $0.40 \pm 0.007$ & 14.32 \\
$4 \times$ & $26.07 \pm 1.76^{*}$ & $17.09 \pm 0.51^{* * *}$ & $2.83 \pm 0.11^{* * *}$ & $7.51 \pm 0.24^{* *}$ & $0.37 \pm 0.009^{* *}$ & $10.15^{* *}$ \\
\hline
\end{tabular}

The significance analysis followed student's $t$-test, ${ }^{* * *}$ means $P \leq 0.001,{ }^{* *}$ means $P \leq 0.01,{ }^{*}$ means $P \leq 0.05$. The S (\%) and $G(\%)$ data means the proportion of Syringyl units or Guaiacyl units in total composition $(C+G+S+H+P+U+0)$. $4 \times$ refers to tetraploid rice, and $2 \times$ refers to diploid rice.

The lignin was measured by pyGC-MS method. The results showed that the lignin content and S/G were significantly lower than the diploid (Table 1). In previous studies, the changes in cell wall composition of tetraploid plants, including a decline in lignin content [4], were found to be consistent with our results.

As the ash in other polyploid plants negatively correlated with cellulose [10], the ash content of tetraploid rice was detected. The content of tetraploid rice straw ash was only 10.15\% (Table 1), while the cellulose content increased (Figure 3). This data is consistent with the previous finding [10]. In summary, the tetraploid straw showed particular cell wall composition with high cellulose and low lignin and ash, implying that tetraploid rice might be an improved feedstock of bioresources.

\subsection{Optimum Enzymatic Hydrolysis Ability of Tetraploid Straw}

Enzymatic hydrolysis of tetraploid was assessed with the AIR and the $2 \% \mathrm{NaOH}$ pretreated AIR. The enzymatic efficiency and the glucose increment were two parameters to present the enzymatic hydrolysis performance. At the initial stage of the enzymatic hydrolysis reaction, the enzymatic 
efficiencies of tetraploid and diploid were only $11.22 \%$ and $10.45 \%$, respectively (Figure $4 a$ ), and they raised to $22.94 \%$ and $17.72 \%$ after alkaline treatment, respectively. These enzymatic reactions gradually saturated within $72 \mathrm{~h}$. The enzyme efficiency of tetraploid at the final stage of hydrolysis reached $62.31 \%$, which showed a $14.51 \%$ increase compared to the diploid. Furthermore, the final efficiency of pretreated tetraploid was as high as $77.60 \%$, an increase of $19.80 \%$ compared to pretreated diploid (Figure 4a). Our results indicated that tetraploid straw shows significant advantages of enzymatic hydrolysis both before and after pretreatment. Furthermore, the hydrolysis efficiency caused by the pretreatment was $15.29 \%$ in tetraploid straw, which was a $4.55 \%$ higher than the diploid, indicating that the advantages of tetraploid in hydrolysis could be enhanced by pretreatment. These advantages could be due to structural differences in tetraploid cell walls.
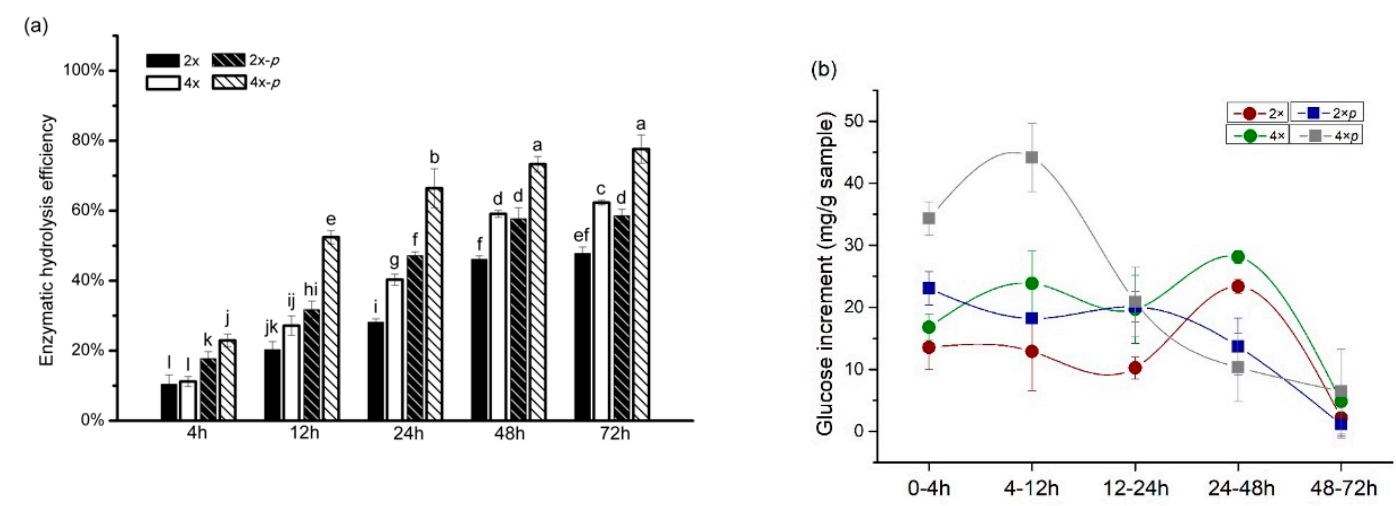

Figure 4. Saccharification of tetraploid rice straw. (a) The efficiency of enzymatic hydrolysate of tetraploid $(4 \times)$, diploid $(2 \times)$, tetraploid after pretreatment $(4 \times-p)$, and the diploid after pretreatment $(2 \times-p)$. (b) Glucose increment over the reaction periods. It reflects the rate of glucose products during enzymatic hydrolysis. The significance analysis followed LSD-test.

In addition to the hydrolysis efficiency, glucose increment was statistically analyzed with the released glucose per gram of samples during hydrolysis. The period at $4-12 \mathrm{~h}$ showed fastest increase of pretreated tetraploid straw. The amount of tetraploid glucose increment was much higher than diploid rice straw over this previous period. This implies that tetraploid rice straw can interact with enzymes more quickly under the same enzyme contents and reaction conditions. Not only that but also non-pretreated tetraploid in the 4-12 $\mathrm{h}$ period had a higher increment than pretreated diploid (Figure $4 \mathrm{~b}$ ), which further confirmed the tetraploid straw showed dominant advantage on the hydrolysis. In addition, an increased peak was only found at $24-48 \mathrm{~h}$ in the non-pretreated rice straws (Figure 4 b), which might be due to low velocity without the pretreatment. In brief, pretreated tetraploid showed a higher reaction ratio, especially in the earlier stages of the hydrolysis, which increased significantly more glucose than other samples (Figure $4 \mathrm{~b}$ ). The high reaction ratio in tetraploid rice straw could be due to structural differences of tetraploid cell walls as well.

In general, changes in cell wall structure include content and structure changes of lignin, cellulose, and hemicellulose. The tetraploid showed decreased lignin and ash content, changes of lignin structure, and increased cellulose content (Figure 3, Table 1). As previously published, these changes can significantly affect the enzymatic hydrolysis process [20-24], which is consistent with our results in the tetraploid straw.

Recent studies have explored the positive effect of $\mathrm{Cd}$ on saccharification efficiency [25], which may be related to the structure of the cell wall. Cd elements were semi-quantitatively determined, coupling with $\mathrm{Si}$ and $\mathrm{Al}$ as the reference elements (Table 2). Surprisingly, the relative proportion of $\mathrm{Cd}$ in tetraploid rice straw cellulose far exceeds that of diploid straw. This also supports the advantages of tetraploid in the enzymatic process. 
Table 2. Elemental normalization semi-quantitative analysis.

\begin{tabular}{ccccc}
\hline Sample & Chemical Element & Standard Sample & Uniformization (Weight) $\%$ & Uniformization (Atomicity)\% \\
\hline \multirow{2}{*}{$2 \times$} & $\mathrm{Al}$ & $\mathrm{Al} 2 \mathrm{O} 3$ & $\mathrm{ND}^{\mathrm{a}}$ & $\mathrm{ND}^{\mathrm{a}}$ \\
& $\mathrm{Si}$ & $\mathrm{SiO} 2$ & 99.55 & 99.89 \\
& $\mathrm{Cd}$ & $\mathrm{Cd}$ & 0.45 & 0.11 \\
\hline \multirow{3}{*}{$4 \times$} & $\mathrm{Al}$ & $\mathrm{Al} 2 \mathrm{O} 3$ & 0.05 & 0.05 \\
& $\mathrm{Si}$ & $\mathrm{SiO} 2$ & 94.8 & 98.61 \\
& $\mathrm{Cd}$ & $\mathrm{Cd}$ & 5.15 & 1.34 \\
\hline
\end{tabular}

a ND, not detected.

\subsection{Observation of Surface Topography before and after Tetraploid Pretreatment}

Because changes of lignin in the tetraploid cell wall might inevitably lead to differences in surface topography, the straw surface and the pretreated sample were observed by SEM. The surface of the diploid straw was smooth, while the tetraploid straw had a rich texture. After pretreatment, the surface of diploid and tetraploid straw showed noticeable swelling and deep folds caused by the removal of some components, such as lignin. The degree of swelling and pleats of the tetraploid was higher than that of diploid, resulting in an increase in contact area with the enzyme (Figure 5). The presence of these ordered textures allows the tetraploid to have not only better physical-mechanical properties in plants but also increases the contact area with the enzyme during the hydrolysis reaction. The surface topography of the tetraploid rice might result from the low lignin content and S/G in tetraploid, shown in Table 1. Therefore, lignin changes might correlate with the loosen cell wall, which makes the tetraploid straws are much more susceptible to the pretreatment process.

Furthermore, the cellulose obtained by removing most of the lignin and hemicellulose were scanned using SEM. This result confirmed that the surface roughness of cellulose was similar and swelling occurred in both tetraploid and diploid after the pretreatment (Figure S1).

\subsection{Fourier Transform Infrared Analysis of the Tetraploid Straw}

The straws before and after pretreatment were spectrally detected by FT-IR to verify the different bands. Three lignin-related absorption bands, 1512, 1320, and $1256 \mathrm{~cm}^{-1}$ were detected (Figure 6). Compared to the untreated diploid straws, the untreated tetraploid sample showed a slight decrease at $1512 \mathrm{~cm}^{-1}$ due to aryl-H vibrations of lignin [26]. The absorption peaks at $1320 \mathrm{~cm}^{-1}$ and $1256 \mathrm{~cm}^{-1}$, respectively, originated from syringyl units and guaiacyl units, went down as well. The intensity of these absorption peaks indicates that the tetraploid lignin level was below the diploid. Furthermore, the FT-IR spectrum showed less S/G in tetraploid than that in diploid rice (Figure 6). This result further confirmed that the $\mathrm{S} / \mathrm{G}$ is low in the tetraploid compared to the diploid by pyGC-MS analysis (Table 1 ). The absorption peak at $1512 \mathrm{~cm}^{-1}$ disappeared after pretreatment, indicating the lignin was dissolved during the pretreatment.

The absorption bands for polysaccharides were found in the FT-IR spectrum as well. The absorption of diploid rice at $1600 \mathrm{~cm}^{-1}$ included not only aromatic skeleton vibrations but also polysaccharide-derived vibrations, and this absorption peak gradually disappeared on the tetraploid and pretreated samples. In addition, the large absorption peaks at 1638 and $1036 \mathrm{~cm}^{-1}$ were carbonyl stretching and polysaccharide vibrations, respectively $[27,28]$, which were present in all samples. The polysaccharide bands showed no significant changes in FT-IR results.

\subsection{Analysis of Cellulose Structure in Tetraploid Straw}

To further investigate cellulose crystallinity of the tetraploid rice, the powder of AIR was measured by XRD. Three peaks at $2 \theta=16.06,22.08$, and 34.75 were characteristic peaks in the crystalline region of cellulose I (Figure 7). Combined with the valley of the amorphous region at $2 \theta=18.43$, the crystallinity index was calculated. The crystallinity index of the tetraploid was $63.22 \%$, and it was $8.07 \%$ lower than that of the diploid. After the pretreatment, the crystallinity indexes decreased to $67.37 \%$ and $57.65 \%$ in diploid and tetraploid straws, respectively. In particular, the pretreated-tetraploid crystallinity was 
$9.72 \%$ lower than that of the pretreated-diploid. The low crystallinity makes cellulase accessible to cellulose hydrolysate and shows high saccharification efficiency (Figure 4a).

Besides cellulose crystallinity, the functional groups in cellulose also contributed to enzymatic saccharification. To explore the functional group changes of the cellulose in the tetraploid, the fingerprint region of the FT-IR spectra of the purified cellulose from rice straw was determined. Two bands of 897 and $1381 \mathrm{~cm}^{-1}$ were observed, which exhibit a typical -CH stretching in cellulose I and asymmetric deformation of - $\mathrm{CH}$ from polysaccharide, respectively [29-31]. Moreover, the peak at 1642 $\mathrm{cm}^{-1}$ corresponds to the stretching vibration of cellulose-bound water, the peaks of 1162 and $1110 \mathrm{~cm}^{-1}$ have been classified into asymmetric stretching of C-O-C and C-O elongation, respectively [32]. All these cellulose bands showed no structural difference between tetraploid and diploid straw. They share the same characteristic peak shape and slightly different peak intensity (Figure S2), indicating that the functional group of cellulose is not the dominant factor for the higher saccharification efficiency of tetraploid. Furthermore, the characteristic absorption peak of the $\mathrm{C}=\mathrm{C}$ aromatic ring representing lignin appeared at $1428 \mathrm{~cm}^{-1}[30,33]$, indicating that there is still a small amount of lignin residue in the process of de-lignification.

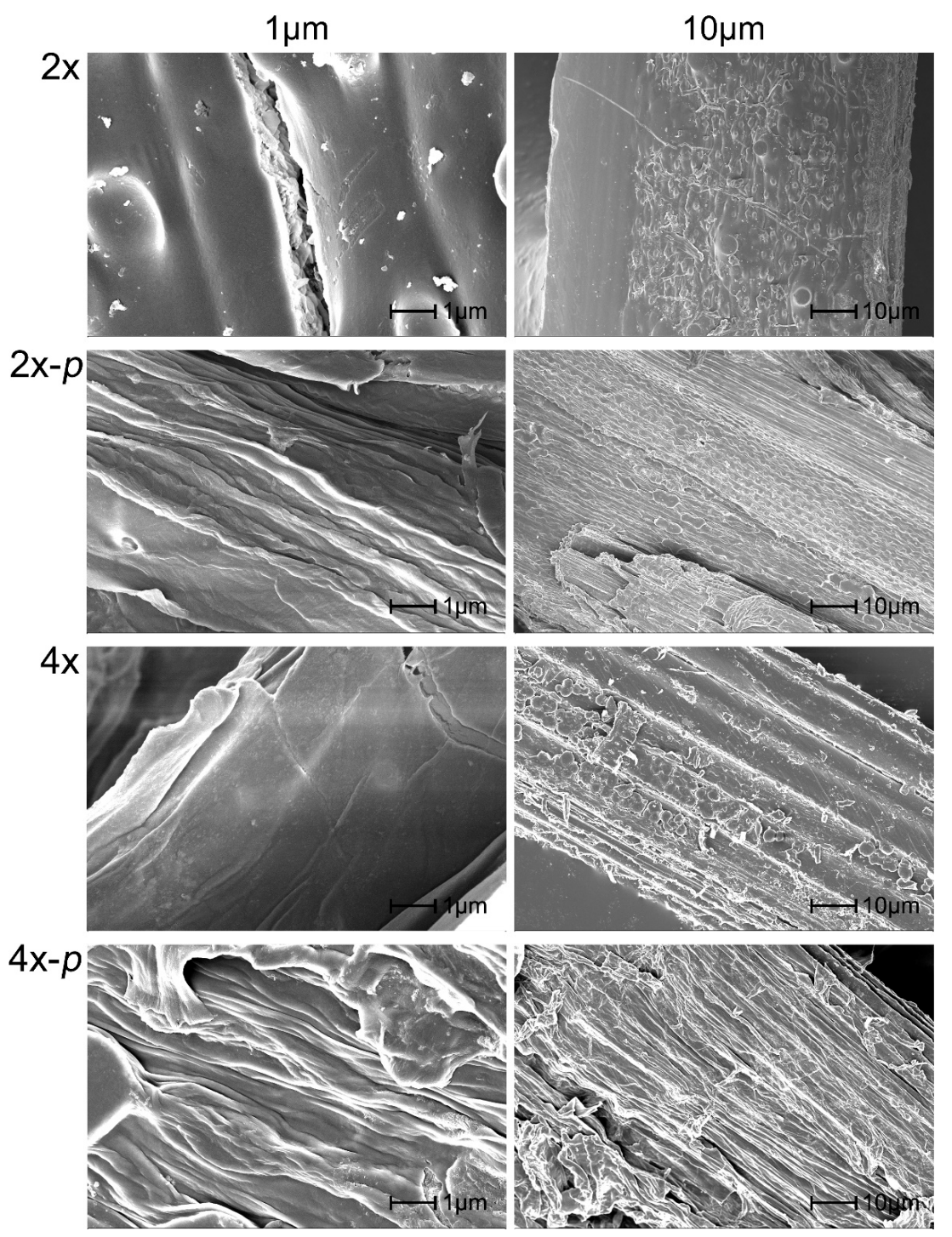

Figure 5. Scanning electron microscope of tetraploid $(4 \times)$, diploid $(2 \times)$, tetraploid after pretreatment $(4 \times-p)$, and the diploid after pretreatment $(2 \times-p)$. 


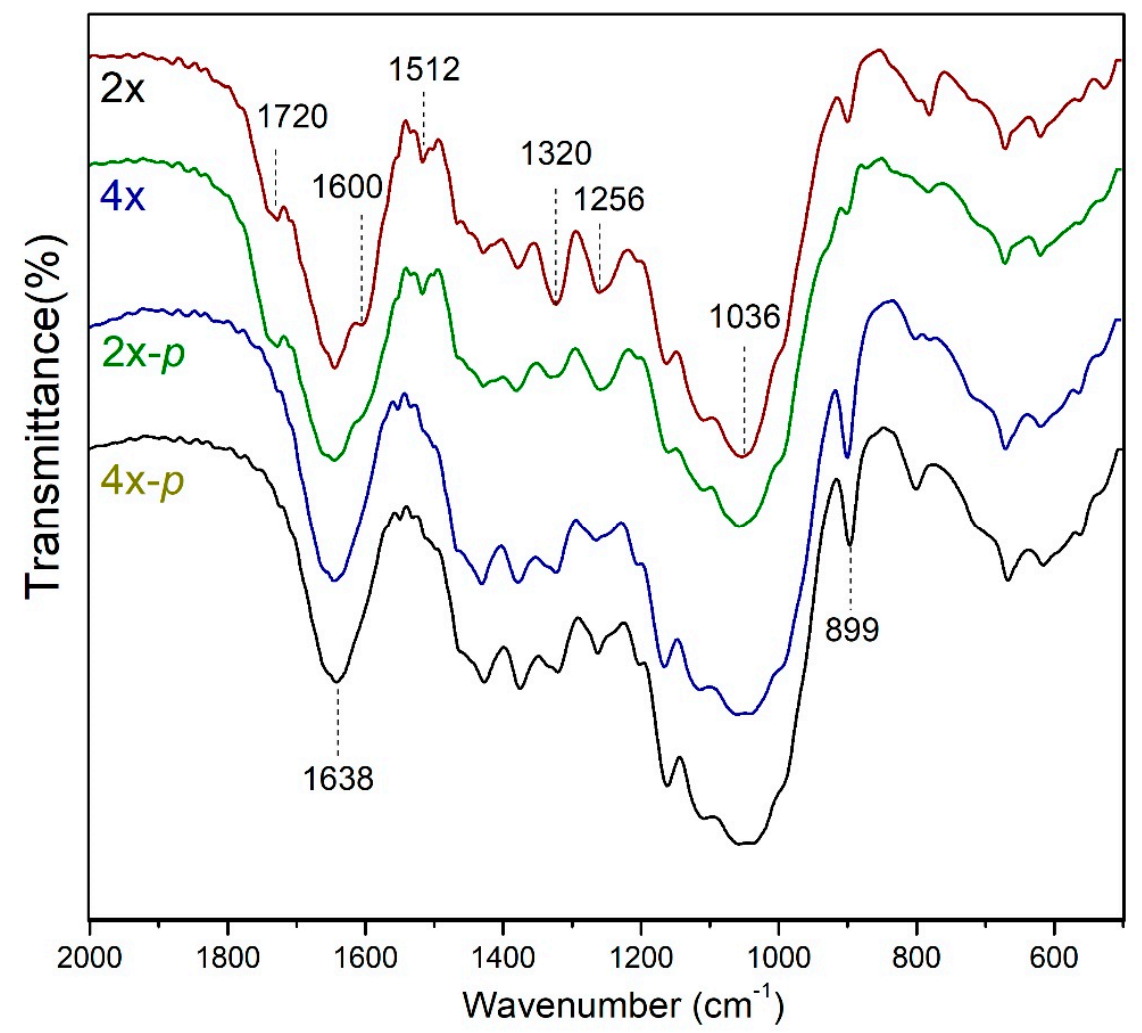

Figure 6. Fourier transform infrared analysis of tetraploid $(4 \times)$, diploid $(2 \times)$, tetraploid after pretreatment $(4 \times-p)$, and the diploid after pretreatment $(2 \times-p)$.

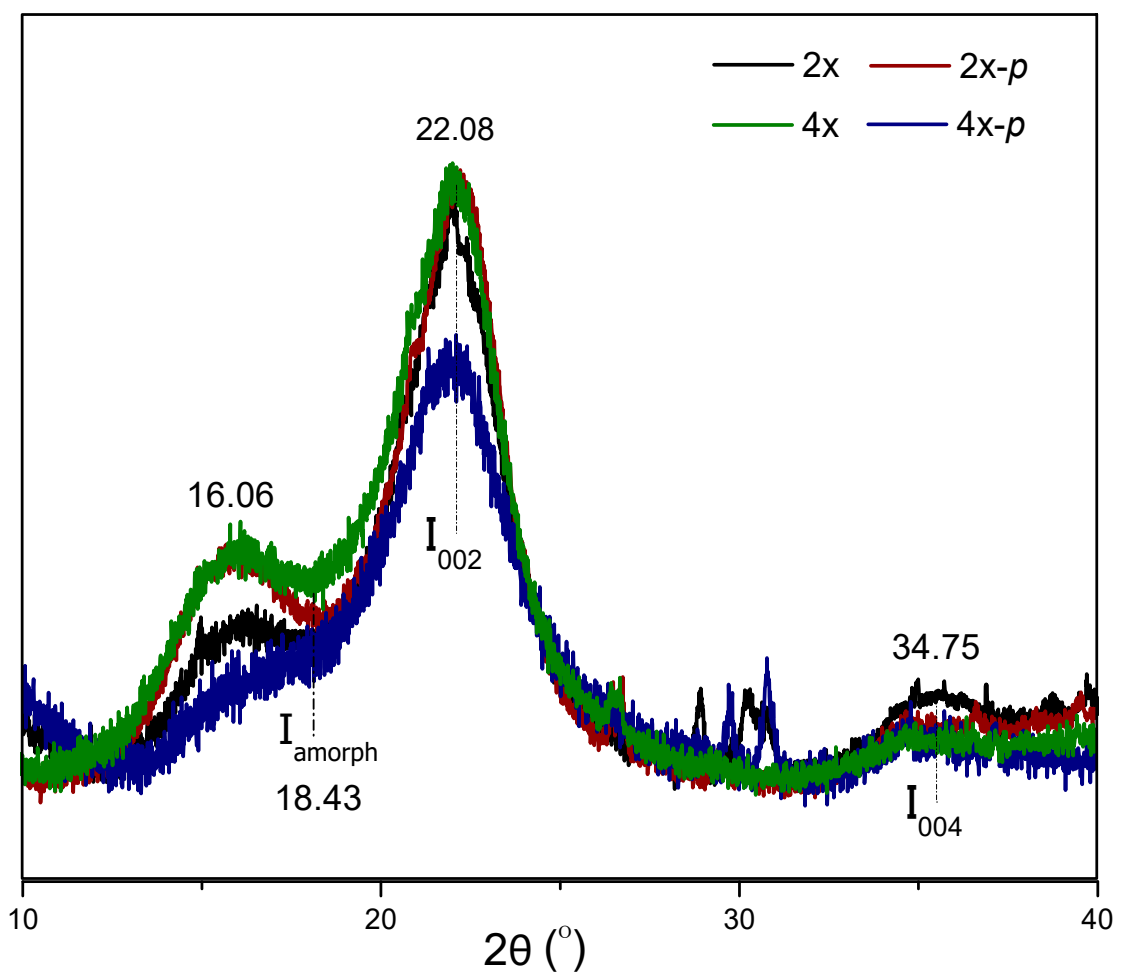

Figure 7. Diffraction of $X$-rays of tetraploid $(4 \times)$, diploid $(2 \times)$, tetraploid after pretreatment $(4 \times-p)$, and the diploid after pretreatment $(2 \times-p)$. 


\section{Conclusions}

Rice straw is an essential green material for biomass utilization, while its utilization of conventional rice straw requires complex pretreatment processes and high cost during the pretreatment. This study revealed that tetraploid rice straw showed enhanced saccharification, implying the potential to simplify the pretreatment and reduce the cost. The innate reduction in lignin content and changes in syringyl units and guaiacyl units directly make the straw more accessible to be pretreated, thereby reducing the use of pretreatment. Besides, decreased cellulose crystallinity can further improve the efficiency of utilization.

Supplementary Materials: The following are available online at http://www.mdpi.com/2073-4360/12/2/340/s1, Figure S1: Surface morphology of cellulose purified from tetraploid $(4 \times)$, diploid $(2 \times)$, tetraploid after pretreatment $(4 \times-p)$, and the diploid after pretreatment $(2 \times-p)$ by scanning electron microscope. Figure S2: FT-IR spectrum of cellulose of tetraploid $(4 \times)$, diploid $(2 \times)$, tetraploid after pretreatment $(4 \times-p)$, and the diploid after pretreatment $(2 \times-p)$.

Author Contributions: Conceptualization, C.C., A.W., and B.W.; data curation, C.C.; formal analysis, C.C.; funding acquisition, A.W.; investigation, B.W.; methodology, C.C., J.C., and J.H.; project administration, C.C., A.W., and B.W.; resources, Z.C. and X.L.; software, J.H.; supervision, A.W. and B.W.; validation, H.L. and S.S.; visualization, C.C.; writing—original draft, C.C.; writing—Review and editing, C.C., A.W., and B.W. All authors have read and agreed to the published version of the manuscript.

Funding: This research was funded by Guangdong Province Science and Technology Projects, grant number 2016A010104012 and National Natural Science Foundation of China (Grant Numbers 31670670, 31670601).

Acknowledgments: We thank X.L. and Z.C. for developing the tetraploid rice and Mirza Faisal Qaseem for checking the English writing before the resubmission.

Conflicts of Interest: There is no conflict of interest with any organization, financial or other, regarding the material discussed in the manuscript.

\section{References}

1. Tadesse, H.; Luque, R. Advances on biomass pretreatment using ionic liquids: An overview. Energy Environ. Sci. 2011, 4, 3913-3929. [CrossRef]

2. Renny-Byfield, S.; Wendel, J.F. Doubling down on genomes: polyploidy and crop plants. Am. J. Bot. 2014, 101, 1711-1725. [CrossRef] [PubMed]

3. Sattler, M.C.; Carvalho, C.R.; Clarindo, W.R. The polyploidy and its key role in plant breeding. Planta 2016, 243, 281-296. [CrossRef]

4. Serapiglia, M.J.; Gouker, F.E.; Hart, J.F.; Unda, F.; Mansfield, S.D.; Stipanovic, A.J.; Smart, L.B. Ploidy Level Affects Important Biomass Traits of Novel Shrub Willow (Salix) Hybrids. Bioenergy Res. 2015, 8, 259-269. [CrossRef]

5. Tavan, M.; Mirjalili, M.H.; Karimzadeh, G. In vitro polyploidy induction: Changes in morphological, anatomical and phytochemical characteristics of Thymus persicus (Lamiaceae). Plant Cell Tissue Organ Cult. 2015, 122, 573-583. [CrossRef]

6. Vergara, F.; Kikuchi, J.; Breuer, C. Artificial Autopolyploidization Modifies the Tricarboxylic Acid Cycle and GABA Shunt in Arabidopsis thaliana Col-0. Sci. Rep. 2016, 6. [CrossRef] [PubMed]

7. Brandt, A.; Grasvik, J.; Hallett, J.P.; Welton, T. Deconstruction of lignocellulosic biomass with ionic liquids. Green Chem. 2013, 15, 550-583. [CrossRef]

8. Lenting, H.B.M.; Warmoeskerken, M. Mechanism of interaction between cellulase action and applied shear force, an hypothesis. J. Biotechnol. 2001, 89, 217-226. [CrossRef]

9. Qian, X.H.; Ding, S.Y.; Nimlos, M.R.; Johnson, D.K.; Himmel, M.E. Atomic and electronic structures of molecular crystalline cellulose I beta: A first-principles investigation. Macromolecules 2005, 38, 10580-10589. [CrossRef]

10. Fabio, E.S.; Volk, T.A.; Miller, R.O.; Serapiglia, M.J.; Kemanian, A.R.; Montes, F.; Kuzovkina, Y.A.; Kling, G.J.; Smart, L.B. Contributions of environment and genotype to variation in shrub willow biomass composition. Ind. Crop. Prod. 2017, 108, 149-161. [CrossRef] 
11. Li, X.; Ximenes, E.; Kim, Y.; Slininger, M.; Meilan, R.; Ladisch, M.; Chapple, C. Lignin monomer composition affects Arabidopsis cell-wall degradability after liquid hot water pretreatment. Biotechnol. Biofuels 2010, 3. [CrossRef] [PubMed]

12. Studer, M.H.; DeMartini, J.D.; Davis, M.F.; Sykes, R.W.; Davison, B.; Keller, M.; Tuskan, G.A.; Wyman, C.E. Lignin content in natural Populus variants affects sugar release. Proc. Natl. Acad. Sci. USA 2011, 108, 6300-6305. [CrossRef] [PubMed]

13. Zhang, Y.; Culhaoglu, T.; Pollet, B.; Melin, C.; Denoue, D.; Barriere, Y.; Baumberger, S.; Mechin, V. Impact of Lignin Structure and Cell Wall Reticulation on Maize Cell Wall Degradability. J. Agric. Food Chem. 2011, 59, 10129-10135. [CrossRef]

14. Taherzadeh, M.J.; Karimi, K. Enzyme-Based Hydrolysis Processes for Ethanol from Lignocellulosic Materials: A Review. Bioresources 2007, 2, 707-738.

15. Lai, V.M.F.; Lu, S.; He, W.H.; Chen, H.H. Non-starch polysaccharide compositions of rice grains with respect to rice variety and degree of milling. Food Chem. 2007, 101, 1205-1210. [CrossRef]

16. Guo, H.; Mendrikahy, J.N.; Xie, L.; Deng, J.; Lu, Z.; Wu, J.; Li, X.; Shahid, M.Q.; Liu, X. Transcriptome analysis of neo-tetraploid rice reveals specific differential gene expressions associated with fertility and heterosis. Sci. Rep. 2017, 7. [CrossRef] [PubMed]

17. He, J.-B.; Zhao, X.-H.; Du, P.-Z.; Zeng, W.; Beahan, C.T.; Wang, Y.-Q.; Li, H.-L.; Bacic, A.; Wu, A.-M. KNAT7 positively regulates xylan biosynthesis by directly activating IRX9 expression in Arabidopsis. J. Integr. Plant Biol. 2018, 60, 514-528. [CrossRef] [PubMed]

18. Bei, X.; Shahid, M.Q.; Wu, J.; Chen, Z.; Wang, L.; Liu, X. Re-sequencing and transcriptome analysis reveal rich DNA variations and differential expressions of fertility-related genes in neotetraploid rice. PLoS ONE 2019, 14. [CrossRef]

19. Chen, L.; Yuan, Y.; Wu, J.; Chen, Z.; Wang, L.; Shahid, M.Q.; Liu, X. Carbohydrate metabolism and fertility related genes high expression levels promote heterosis in autotetraploid rice harboring double neutral genes. Rice 2019, 12. [CrossRef]

20. Jiang, B.; Wang, W.; Gu, F.; Cao, T.; Jin, Y. Comparison of the substrate enzymatic digestibility and lignin structure of wheat straw stems and leaves pretreated by green liquor. Bioresour. Technol. 2016, 199, 181-187. [CrossRef]

21. Li, M.; Si, S.; Hao, B.; Zha, Y.; Wan, C.; Hong, S.; Kang, Y.; Jia, J.; Zhang, J.; Li, M.; et al. Mild alkali-pretreatment effectively extracts guaiacyl-rich lignin for high lignocellulose digestibility coupled with largely diminishing yeast fermentation inhibitors in Miscanthus. Bioresour. Technol. 2014, 169, 447-454. [CrossRef] [PubMed]

22. Sun, S.-L.; Sun, S.-N.; Wen, J.-L.; Zhang, X.-M.; Peng, F.; Sun, R.-C. Assessment of integrated process based on hydrothermal and alkaline treatments for enzymatic saccharification of sweet sorghum stems. Bioresour. Technol. 2015, 175, 473-479. [CrossRef]

23. Wu, X.; Tang, W.; Huang, C.; Huang, C.; Lai, C.; Yong, Q. The effects of exogenous ash on the autohydrolysis and enzymatic hydrolysis of wheat straw. Bioresour. Technol. 2019, 286. [CrossRef] [PubMed]

24. Xu, N.-J.; Henkemeyer, M. Ephrin reverse signaling in axon guidance and synaptogenesis. Semin. Cell Dev. Biol. 2012, 23, 58-64. [CrossRef] [PubMed]

25. Cheng, S.; Yu, H.; Hu, M.; Wu, Y.; Cheng, L.; Cai, Q.; Tu, Y.; Xia, T.; Peng, L. Miscanthus accessions distinctively accumulate cadmium for largely enhanced biomass enzymatic saccharification by increasing hemicellulose and pectin and reducing cellulose CrI and DP. Bioresour. Technol. 2018, 263, 67-74. [CrossRef] [PubMed]

26. Stewart, D.; Morrison, I. FT-IR spectroscopy as a tool for the study of biological and chemical treatments of barley straw. J. Sci. Food Agric. 1992, 60, 431-436. [CrossRef]

27. Joachim, G.; Jung, H.; Himmelsbach, D. Isolation and characterization of wheat straw lignin. J. Agric. Food Chem. 1989, 37. [CrossRef]

28. Lawther, M.; Sun, R.B.; Banks, W. Fractional Characterization of Wheat Straw Lignin Components by Alkaline Nitrobenzene Oxidation and FT-IR Spectroscopy. J. Agric. Food Chem. 1996, 44. [CrossRef]

29. Le Troedec, M.; Peyratout, C.S.; Smith, A.; Chotard, T. Influence of various chemical treatments on the interactions between hemp fibres and a lime matrix. J. Eur. Ceram. Soc. 2009, 29, 1861-1868. [CrossRef]

30. Sun, X.F.; Xu, F.; Sun, R.C.; Fowler, P.; Baird, M.S. Characteristics of degraded cellulose obtained from steam-exploded wheat straw. Carbohydr. Res. 2005, 340, 97-106. [CrossRef]

31. Zhong, C.; Wang, C.; Huang, F.; Jia, H.; Wei, P. Wheat straw cellulose dissolution and isolation by tetra-n-butylammonium hydroxide. Carbohydr. Polym. 2013, 94, 38-45. [CrossRef] [PubMed] 
32. Fang, J.M.; Fowler, P.; Tomkinson, J.; Hill, C.A.S. Preparation and characterisation of methylated hemicelluloses from wheat straw. Carbohydr. Polym. 2002, 47, 285-293. [CrossRef]

33. Kristensen, J.B.; Thygesen, L.G.; Felby, C.; Jorgensen, H.; Elder, T. Cell-wall structural changes in wheat straw pretreated for bioethanol production. Biotechnol. Biofuels 2008, 1. [CrossRef] [PubMed]

(C) 2020 by the authors. Licensee MDPI, Basel, Switzerland. This article is an open access article distributed under the terms and conditions of the Creative Commons Attribution (CC BY) license (http://creativecommons.org/licenses/by/4.0/). 